\title{
FOTOSSENSIBILIZAÇÃO HEPATÓGENA EM BOVINOS NO SUL DO RIO GRANDE DO SUL
}

\author{
HEPATOGENOUS PHOTOSENSITIZATION IN CATTLE \\ IN SOUTHERN RIO GRANDE DO SUL, BRAZIL
}

\author{
Adriana Costa da Motta ${ }^{1}$ Gabriela Riet-Correa Rivero ${ }^{2}$ Ana Lucia Schild ${ }^{3}$ \\ Franklin Riet-Correa ${ }^{3}$ Maria del Carmen Méndez ${ }^{3}$, João Luiz Ferreira ${ }^{4}$
}

RESUMO

São descritos aspectos epidemiológicos e patológicos de 19 surtos de fotossensibilização observados em bovinos na região sul do Rio Grande do Sul, no período entre 1984 e 1997. A doença ocorre, principalmente, nos meses de outono e primavera com morbidade de $0,08 \%$ a $64 \%$ e mortalidade de 0 a $14 \%$. Todas as categorias são afetadas e as áreas onde ocorrem os surtos se caracterizam por campos planos e baixos, freqüentemente utilizados para o plantio de arroz irrigado ou pastagens de azevém, trevo e aveia ou, ainda, em áreas similares com vegetação nativa. A enfermidade caracteriza-se, clinicamente, por depressão, anorexia, salivação intensa e fotossensibilização observada nas áreas de pele despigmentadas e desprovidas de pêlos como o focinho, ao redor dos olhos, virilha, úbere e vulva. Nos casos severos, observam-se lesões caracterizadas por ressecamento, rachaduras e desprendimento da pele, principalmente do dorso e membros, deixando à mostra superfície ulcerada. As lesões macroscópicas são características de insuficiência hepática, observando-se icterícia, fígado aumentado de tamanho com coloração amarelada, aumento de tamanho da vesícula biliar, presença de líquido nas cavidades e, em alguns casos, edema do tecido subcutâneo e peritônio. As lesões histológicas caracterizam-se, principalmente, por lesões degenerativas do parênquima hepático, observando-se tumefação e vacuolização difusa ou zonal dos hepatócitos. Observa-se, também, apoptose ou focos de necrose distribuídos aleatoriamente pelo parênquima, presença de megalócitos e, ainda, fibroplasia dos espaços porta e proliferação de células de ductos biliares. A enfermidade é caracterizada como fotossensibilização hepatógena relacionada a dano primário ao parênquima hepático, de etiologia não determinada, uma vez que foram descartadas as principais causas conhecidas de fotossensibilização de origem hepática em bovinos.
Palavras-chave: fotossensibilização, fotossensibilização hepatógena, bovinos.

\section{SUMMARY}

The epidemiological and pathological aspects of 19 outbreaks of photosensitization in cattle, observed in southern Brazil, between 1984 e 1997 were studied. The disease occurs mainly in spring and fall with morbidity of $0.08 \%$ to $64 \%$ and mortality of 0 to $14 \%$. Cattle of all ages are affected. The pastures on which outbreaks occur are characterized by low, flat and wet land, used alternatedly for rice or other crops and natural or cultured pastures of clover, oat and ryegrass. The disease is characterized clinically by depression, anorexia, salivation and photosensitization of white or slightly colored and hairless skin such as muzzle, nostrils, eyelids, udder, groin and vulva. In severe cases the skin, mainly of dorsal midline and legs, was thickened, necrotic and sloughed revealing a raw area of subcutaneous tissue. The macroscopic lesions were tipically related to hepatic insuficiency. Jaundice, yellow to orange discoloration and swelling of the liver, edema of the gall bladder, excess of serous fluid in body cavities and occasionally subcutaneous and peritoneal edema were observed. The histological changes are characterized by degenerative changes of hepatocytes that are diffusely or zonal vacuolated and swollen. Individual or ramdomly scattered foci of hepatocellular necrosis, bile ductular proliferation, and portal fibrosis were also observed. The disease was characterized as a bovine hepatogenous photosensitivity syndrome resulting from primary damage to the liver parenchyma. The etiology is unknown and the main known causes of hepatogenous photosensitivity in cattle were ruled out.

Key words: photosensitivity, hepatogenous photosensitivity, cattle.

\footnotetext{
${ }^{1}$ Médico Veterinário MSc.

${ }^{2}$ Bolsista do CNPq -PIBIC, Universidade Federal de Pelotas (UFPel).

${ }^{3}$ Laboratório Regional de Diagnóstico, Faculdade de Veterinária, UFPel, 96010-900, Pelotas RS. Bolsistas do CNPq. E-mail: alschild@ zaz.com..br. Autor para correspondência.

${ }^{4}$ Laboratório Regional de Diagnóstico, Faculdade de Veterinária, UFPel.

Recebido para publicação em 10.12.98. Aprovado em 31.03.99
} 


\section{INTRODUÇÃO}

A ocorrência de fotossensibilização hepatógena em bovinos tem sido mencionada em diversos países e atribuída a plantas hepatotóxicas, a toxinas de algas do gênero Microcystis e a saponinas presentes em plantas como Panicum spp., Tribulus terrestris, Brachiaria decumbens e outras, que levam à deposição de material cristalóide nos ductos biliares, células de Kupffer e parênquima hepático (ROWE, 1989; KELLERMAN et al., 1990; HOLLAND et al., 1991; MILES et al., 1993; KELLY, 1993; TAPIA et al., 1994; LEMOS et al., 1997). As micotoxicoses eczema facial, causada pela esporidesmina produzida pelo fungo Pithomyces chartarum, e lupinose, causada pelas micotoxinas phomopsin A e B, produzidas por Phomopsis leptostromiformis, que parasita Lupinus spp. são, também, causas conhecidas de enfermidade hepática associadas à fotossensibilização (ROWE, 1989; KELLERMAN et al., 1990).

Surtos de fotossensibilização, de etiologia incerta têm sido descritos em bovinos em pastagens de trevo vermelho (CASTEEL et al., 1991) ou alimentados com feno de alfafa contaminado por fungos (MARASAS \& KELLERMAN, 1978; ROWE, 1989; CASTEEL et al., 1995). Têm sido descritos, também, surtos de fotossensibilização em bovinos que consomem Cynodon dactylon (grama bermuda) logo após geadas (MARASAS E KELLERMAN 1978). Fungos como Periconia minutissima, Myrothecium spp., Alternaria spp., Rhizoctonia spp. e diversas especies de Aspergillus têm sido isolados dos diferentes vegetais, porém não tem sido comprovada a importância desses agentes na etiologia da enfermidade (MARASAS \& KELLERMAN, 1978; CASTEEL et al., 1991; CASTEEL $\boldsymbol{e t}$ al., 1995).

A insuficiência hepática que leva a fotossensibilização pode resultar de dano primário ao sistema biliar ou dano primário ao parênquima hepático, podendo observar-se, neste caso, lesões degenerativas; necrose zonal associada a lesões degenerativas; ou degeneração gordurosa difusa (ROWE, 1989; KELLERMAN et al., 1990). Os mecanismos responsáveis pela retenção de filoeritrina por oclusão do sistema biliar estão parcialmente definidos, porém, pouco é conhecido sobre a patogenia da fotossensibilização resultante de injúria ao parênquima hepático (KELLERMAN et al., 1990).

As lesões de fotossensibilização tendem a ocorrer quando o dano hepático é generalizado (YAGER \& SCOTT, 1993). Os agentes que causam alteração difusa no parênquima hepático parecem levar à retenção de filoeritrina por interferência na drenagem canalicular de bile como resultado da tumefação dos hepatócitos, embora outros mecanismos possam estar envolvidos (ROWE, 1989). Quando o dano ao parênquima hepático é zonal, a fotossensibilização é incomum, porque um número suficiente de hepatócitos, comumente, escapa desse dano, removendo a filoeritrina da circulação (ROWE, 1989; YAGER \& SCOTT, 1993).

Surtos de fotossensibilização hepatógena em bovinos têm ocorrido, freqüentemente, na área de influência do Laboratório Regional de Diagnóstico (LRD) da Faculdade de Veterinária da Universidade Federal de Pelotas, sem que tenham sido determinadas as suas causas (SCHILD et al., 1992). Em levantamento realizado sobre as doenças tóxicas dos bovinos diagnosticadas no LRD no período de 1978 a 1997, fotossensibilização hepatógena abrange um percentual de $13 \%$, demonstrando a importância da enfermidade na região.

O objetivo do presente trabalho é descrever os aspectos epidemiológicos e patológicos de 19 surtos de fotossensibilização hepatógena em bovinos observados entre os anos de 1984 e 1997 na área de influência do LRD.

\section{MATERIAL E MÉTODOS}

Foram estudados 19 surtos de fotossensiblização hepatógena diagnosticados no Laboratório Regional de Diagnóstico (UFPel) ocorridos entre 1984 e 1997. Para o estudo epidemiológico, foram realizadas visitas aos estabelecimentos onde ocorreram os surtos, observando-se a época do ano de ocorrência da enfermidade, as categorias afetadas, os sinais clínicos apresentados, os dados de morbidade e mortalidade e o tipo de campo existente em cada área onde a doença ocorria.

$\mathrm{O}$ estudo da patologia macroscópica foi realizado em 16 bovinos que morreram espontaneamente ou foram sacrificados e necropsiados. Para o estudo microscópico das lesões, além do material colhido nas necropsias, foram utilizadas, também, amostras de fígados colhidas de necropsias realizadas por veterinários de campo e enviadas ao laboratório e biopsias hepáticas realizadas em animais afetados que não morreram. Os tecidos para a histopatologia foram fixados em formol a $10 \%$, embebidos em parafina, cortados com $6 \mu \mathrm{m}$ de espessura e corados pela hematoxilina e eosina.

Em cada estabelecimento onde a doença foi diagnosticada, os potreiros eram percorridos para a observação das áreas à procura de plantas conhecidas como causadoras de fotossensibilização hepatógena e, ainda, à procura de matas nativas. Foi determinada a flora botânica das áreas onde ocorreram 
seis dos 19 surtos, sendo que em dois estabelecimentos foram colocadas gaiolas de arame de aproximadamente $1 \mathrm{~m}^{2}$, em áreas representativas da vegetação que ocorria no potreiro onde os animais tinham apresentado sinais clínicos da enfermidade. As gaiolas e os potreiros foram observados a cada 2 meses, anotando-se as espécies vegetais existentes ${ }^{1}$.

Foram coletadas e analisadas, pelo método de lavagem (TOKARNIA et al., 1979), amostras de vegetação onde foram observados animais doentes em 15 dos 19 surtos para identificação da presença de esporos do fungo Pithomyces chartarum.

Amostras de pastagens onde ocorreram cinco dos 19 surtos foram analisadas no Laboratório de Bacteriologia e Micologia da Faculdade de Veterinária da Universidade Federal de Pelotas (UFPel) com o objetivo de isolar fungos. As amostras de fungos isoladas foram enviadas para o Departamento de Fitossanidade da Faculdade de Agronomia da UFPel para a caracterização final.

\section{RESULTADOS}

Os municípios onde a doença foi observada, as categorias de bovinos afetadas, a época do ano de ocorrência da enfermidade e o tipo de campo em que os animais estavam no momento do aparecimento dos sinais clínicos, bem como os dados de morbidade, mortalidade e número dos surtos são apresentados na tabela 1 .

A enfermidade foi observada em animais de diversas raças como Holandês, Charolês, Hereford, Shorthorn, cruza Charolês, cruza Shorthorn e cruza Zebu. Os sinais clínicos eram depressão, anorexia, salivação intensa, febre em alguns casos, e lesões de fotossensibilização, que variavam de leves a severas, afetando as áreas de pele desprovidas de pêlos como focinho, ao redor dos olhos, vulva, períneo, úbere e áreas de pele despigmentadas. Essas lesões caracterizavam-se por dermatite, que levava ao desprendimento da pele, deixando à mostra áreas de tecido subcutâneo avermelhadas e inflamadas. Podiam-se observar, também, edema de membros, conjuntivite com corrimento ocular purulento, cegueira em alguns casos e lesões ulcerativas na face ventral da língua. Em bovinos de pelagem clara, severamente afetados, as lesões podiam ser generalizadas, levando os animais a perder parte da pele que se apresentava ressecada, com rachaduras e úlceras (figura 1). Observaram-se, ainda, em alguns casos, infecção secundária por miíase, diarréia, agressividade e incoordenação motora. A evolução da enfermidade variava de 7 a 20 dias e alguns animais recuperavam-se. Em quatro dos 19 surtos, não ocorreram mortes e os animais recuperaram-se após um período de até 20 dias.
As lesões macroscópicas caracterizaramse por: icterícia generalizada, fígado aumentado de tamanho, de consistência firme ao corte, com coloração alaranjada ou amarelada. A vesícula biliar estava aumentada de tamanho e apresentava conteúdo espesso e escuro. Havia líquido amarelado nas cavidades torácica e abdominal e edema do tecido subcutâneo e peritônio. A intensidade destas lesões variava de discreta a acentuada. Em alguns casos, observou-se, adicionalmente, urina de cor escura e edema da pelve renal. Nas amostras de fígado enviadas ao laboratório, o órgão tinha superfície capsular esbranquiçada e vesícula biliar distendida com conteúdo escuro e espesso.

As lesões histológicas observadas nos fígados dos bovinos estudados caracterizaram-se por degeneração hepatocelular, os hepatócitos estavam tumefeitos e vacuolizados; observaram-se células apoptóticas e megalócitos; e, ainda, proliferação de tecido conjuntivo fibroso nos espaços porta e proliferação de células de ductos biliares (Figura 3). Infiltrado inflamatório, principalmente, mononuclear era observado nos espaços porta e, ocasionalmente, no parênquima hepático. Retenção biliar intracelular, intracanalicular e intraductal eram freqüentemente observadas. Essas lesões podiam variar em intensidade e distribuição. Hepatócitos aumentados de tamanho, vacuolizados, com aspecto esponjoso eram observados difusamente distribuídos pelo parênquima ou mais localizados nas áreas centrolobular a mediozonal (figura 2) ou periportal. Em alguns casos, foram observados também focos de necrose com infiltrado de células mononucleares distribuídos aleatoriamente no parênquima hepático e inclusões intracitoplasmáticas eosinofílicas nos hepatócitos. Em um bovino, observou-se megalocitose difusa e invaginações nucleares em forma de ferradura ou de pseudoinclusões. Lesões renais caracterizadas pela presença de cilindros hialinos ou granulosos na luz dos túbulos da cortical e da medular; fluido proteináceo no espaço de Bowman de alguns glomérulos; infiltrado inflamatório mononuclear, distribuído em focos na cortical e na junção corticomedular; além de congestão e degeneração das células dos túbulos da cortical e medular foram observadas também em alguns animais. As lesões histológicas observadas na pele dos bovinos caracterizaram-se por hiperqueratose, presença de úlceras na epiderme com formação de crostas acompanhadas de infiltrado inflamatório de polimorfonucleares e mononucleares que se distribuíam até a derme. Os demais órgãos da cavidade abdominal e órgãos da cavidade torácica não apresentaram lesões significativas. 
Tabela 1 - Dados epidemiológicos de 19 surtos de fotossensibilização hepatógena em bovinos, observados na área de influência do Laboratório Regional de Diagnóstico, UFPel, no período entre 1984 e 1997.

\begin{tabular}{|c|c|c|c|c|c|c|c|}
\hline Surto & Mês/Ano & Município & Categorias Afetadas & $\begin{array}{l}\text { Total } \\
\text { de ani- } \\
\text { mais }\end{array}$ & $\begin{array}{c}\text { Morb. }{ }^{1} \\
\%\end{array}$ & $\begin{array}{c}\text { Mort. }^{2} \\
\%\end{array}$ & Tipo de campo \\
\hline 1 & $6-7-8 / 84$ & Pedro Osório & Vacas & 64 & 35,00 & 14,00 & lavoura de soja não colhida \\
\hline 2 & $7-8 / 88$ & Arroio Grande & Vacas-terneiros & 550 & 10,00 & 1,09 & $\begin{array}{l}\text { resteva de soja do ano anterior com azevém; } \\
\text { restevas de soja de } 2 \text { anos ou mais }\end{array}$ \\
\hline 3 & $3-4 / 90$ & Pedro Osório & Novilhas-vacas & 250 & 1,60 & 0.80 & resteva de arroz do ano anterior \\
\hline 4 & $3-4 / 90$ & Pedro Osório & Touros-novilhas & 17 & 17,60 & 11,76 & $\begin{array}{l}\text { resteva de arroz do ano anterior; resteva de aze- } \\
\text { vém do ano anterior }\end{array}$ \\
\hline 5 & $4 / 90$ & Dom Pedrito & Vacas-vaquilhonas & 230 & 0,86 & 0,86 & resteva de arroz de 2 a 3 anos com azevém \\
\hline 6 & $5 / 90$ & Pelotas & Terneiros 1 ano e meio & 1800 & 0,11 & - & resteva de arroz de anos anteriores \\
\hline 7 & $9 / 91$ & Arroio Grande & Terneiros 1 ano & 231 & 41,12 & 2,16 & pastagem de azevém; resteva de arroz de 3 anos; \\
\hline 8 & $9 / 91$ & Arroio Grande & Terneiros 1 ano & 500 & 28,00 & 11,00 & $\begin{array}{l}\text { azevém em resteva de sorgo e milho do ano } \\
\text { anterior }\end{array}$ \\
\hline 9 & $8-9 / 91$ & Pelotas & Novilhos & 700 & 7,41 & _ & resteva de arroz e soja do ano anterior \\
\hline 10 & $9 / 91$ & São Lourenço & Vacas & 140 & 64,00 & 5,70 & resteva de arroz de 4 anos \\
\hline 11 & $5-6 / 93$ & Santa Vitória & Novilhos & 270 & 0,74 & 0,37 & resteva de arroz de 3 anos \\
\hline 12 & $10-11 / 93$ & Rio Grande & Vacas e terneiros & 124 & 12,90 & - & $\begin{array}{l}\text { azevém em resteva de capim de Rhodes de } 3 \text { anos; } \\
\text { azevém em resteva de cornichão, trevo e aveia de } \\
4 \text { anos; pastagem de azevém; campo nativo com } \\
\text { azevém; azevém em resteva de arroz de } 4 \text { anos } \\
\text { campo nativo e resteva de arroz do ano anterior }\end{array}$ \\
\hline $\begin{array}{l}15 \\
14\end{array}$ & $5-6-7 / 94$ & Rio Grande & Novilhos & $\begin{array}{c}50 \\
600\end{array}$ & $\begin{array}{l}2,03 \\
1,33\end{array}$ & $0, \overline{33}$ & campo nativo; resteva de arroz de anos anteriores \\
\hline 15 & $5 / 96$ & Rio Grande & Terneiros & 309 & 0,32 & 0,32 & $\begin{array}{l}\text { campo nativo; resteva de arroz de } 2 \text { anos e resteva } \\
\text { de soja de } 3 \text { anos }\end{array}$ \\
\hline 16 & $12 / 96-1 / 97$ & Rio Grande & $\begin{array}{l}\text { Vaquilhonas e ternei- } \\
\text { ros }\end{array}$ & 4500 & 0,08 & 0,08 & campo nativo; resteva de arroz de anos anteriores \\
\hline 17 & 9/97 & Barra do Ribeiro & Novilhas & 398 & 20,10 & 4,27 & resteva de arroz do ano anterior \\
\hline 18 & $10-11-12 / 97$ & Rio Grande & Vacas e terneiros & 211 & 14,69 & 5,21 & resteva de arroz do ano anterior \\
\hline 19 & $12 / 97$ & Arroio Grande & Novilhos & 1000 & 1,00 & 0,40 & $\begin{array}{l}\text { resteva de arroz do ano anterior e resteva de arroz } \\
\text { de anos anteriores. }\end{array}$ \\
\hline
\end{tabular}

${ }^{1}$ Morb.: morbidade.

A determinação da flora botânica das áreas onde ocorreram 6 surtos demonstrou que as espécies vegetais dominantes estavam representadas por Cynodon dactylon, Axonopus sp., Paspalum paludivagum, Paspalum spp. e Leersia sp. nas restevas de arroz que tinham mais de um ano e nas áreas de campo nativo. Nessas áreas, observaram-se ainda, em quantidades menores, outras espécies vegetais como Panicum miliaceum, Poligonum puntactum, Eragrostis sp., Sisyrinchium sp., Verbena sp., Alternantera sp., Baccharis spp., Echinochloa sp., Rumex sp., Oxalis sp., Sorgastrum sp e Anagalis arvensis. Nas áreas onde haviam sido plantadas pastagens como azevém (Lolium multiflorum), capim de rhodes (Chloris gayana) cornichão (Lotus corniculatus), trevos (Trifolium spp.) e aveia (Avena sativa) observaramse quantidades significativas desses vegetais até um ano após a cultura, que diminuiam gradualmente dando lugar às espécies observadas nas restevas antigas ou em campos nativos. Nas restevas de arroz do ano havia a predominância de vegetais como Juncus bufonius, Echinochloa cruzgalis, Sagitaria montevidensis e Leersia hexandra. Em um dos surtos estudados, no campo em que estavam os bovinos, havia Senecio spp. e Echium plantagineum em pequenas quantidades. Num outro surto, os animais haviam permanecido antes do aparecimento dos sinais clínicos, em áreas com quantidades significativas de Senecio spp.

Em 5 amostras coletadas no estabelecimento onde ocorreu o surto $\mathrm{n}^{\circ} 2$, foram encontrados entre 5.000 e 25.000 esporos de Pithomyces chartarum por grama de pasto. Em uma amostra coletada no local onde ocorreu o surto $\mathrm{n}^{\circ} 8$, foram encontrados 300.000 esporos de Pithomyces chartarum. Nas demais amostras, não foram encontrados esporos desse fungo. 


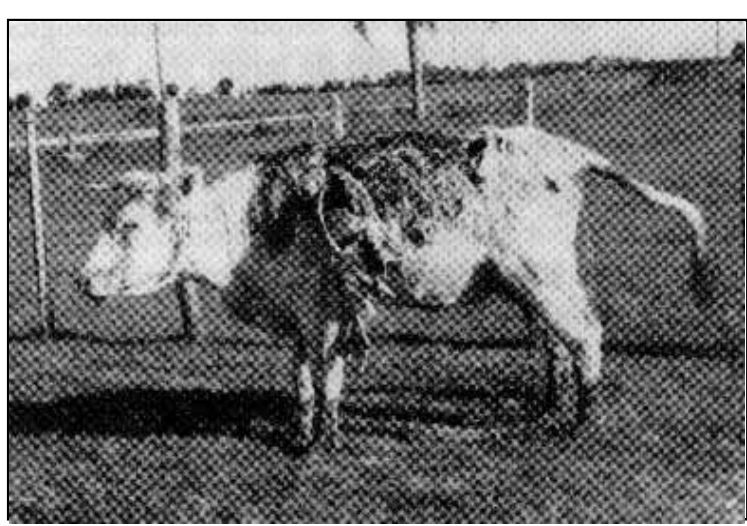

Figura 1 - Lesões de fotossensibilização com rachaduras e perda de pele da região dorso-lateral em um bovino com fotossensibilização hepatógena do surto $\mathrm{n}^{\mathrm{o}} 3$.

O fungo Periconia minutissima foi isolado da vegetação colhida na área onde ocorreu o surto $\mathrm{n}^{\mathrm{o}} 11$. Na amostra de Leersia $\mathrm{sp}$. coletada na área onde ocorreu o surto $\mathrm{n}^{\circ} 14$, foi isolado Chaetomium spp. Na amostra de Echinochloa cruzgalis da área onde se observou o surto $\mathrm{n}^{\circ} 19$, foi isolado Pestalotia spp.

\section{DISCUSSÃO}

A fotossensibilização hepatógena observada em bovinos no sul do Rio Grande do Sul é uma enfermidade que ocorre, principalmente, nos meses de outono e primavera, em áreas de campos baixos e planos, utilizados rotativamente para o plantio de arroz, soja, milho e sorgo ou, ainda, em pastagens de azevém, trevo e aveia e em campo nativo. A enfermidade acomete todas as categorias e traz perdas econômicas consideráveis, uma vez que a morbidade pode chegar a $64 \%$ e a mortalidade, em alguns surtos, chega a $14 \%$.

Lesões macroscópicas de icterícia, alteração na cor, tamanho e consistência do fígado demonstram que a enfermidade se caracteriza por insuficiência hepática com retenção de filoeritrina e conseqüente fotodermatite. Lesões similares são observadas em outras hepatotoxicoses que cursam com fotossensibilização em bovinos (KELLERMAN et al., 1990).

As lesões histológicas caracterizaram-se por tumefação e degeneração dos hepatócitos, com distribuição difusa, periportal ou centrolobular a mediozonal, associadas ou não à necrose. Lesões similares têm sido descritas nas hepatotoxicoses que levam à fotossensibilização por lesão hepatocelular primária (ROWE, 1989; KELLERMAN et al.,1990). Parece evidente que as lesões degenerativas do pa- rênquima associadas às lesões do sistema biliar, nesses casos, foram responsáveis pela retenção de filoeritrina e conseqüente fotodermatite. $\mathrm{O}$ mecanismo de retenção de filoeritrina é complexo e, certamente, dependente de diversos fatores além do tipo e localização das lesões. Isso é evidenciado pelo fato de que outras hepatotoxicoses com lesões acentuadas nos hepatócitos nem sempre causam fotossensibilização (KELLERMAN et al., 1990). É provável que a retenção de filoeritrina ocorra em conseqüência da interferência na drenagem da bile pela tumefação dos hepatócitos (ROWE, 1989). Aparentemente, esse poderia ser o principal mecanismo de retenção da filoeritrina nos casos de fotossensibilização descritos neste trabalho. Lesões histológicas renais inespecíficas observadas em alguns animais são, também, descritas em outras hepatotoxicoses que causam fotossensibilização (MÉNDEZ, 1993)

Nas áreas onde ocorreram os surtos da doença, não foram encontradas plantas hepatotóxicas conhecidas como causa de fotossensibilização em bovinos. Senecio spp. e Echium plantagineum foram observadas em alguns estabelecimentos, porém as alterações macroscópicas e histológicas observadas não eram características das intoxicações causadas por essas plantas. Apenas um bovino apresentou megalocitose difusa e invaginações nucleares semelhantes às observadas na intoxicação por Senecio spp. Isso poderia indicar que, nesse surto, houve o envolvimento de alcalóides pirrolizidínicos na etiologia da enfermidade.

A possibilidade de a enfermidade ser causada pela esporidesmina foi descartada, uma vez que somente uma amostra de vegetação apresentou um número expressivo de esporos de Pithomyces chartarum, sendo que as lesões histológicas não foram características dessa intoxicação.

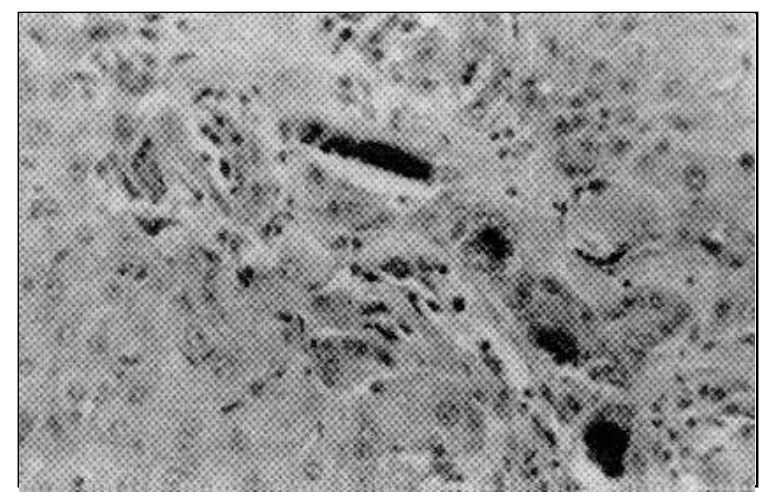

Figura 2 - Vacuolização de hepatócitos da região centrolobular e mediozonal em um bovino com fotossensibilização hepatógena do surto 19. (HE, 10x). 


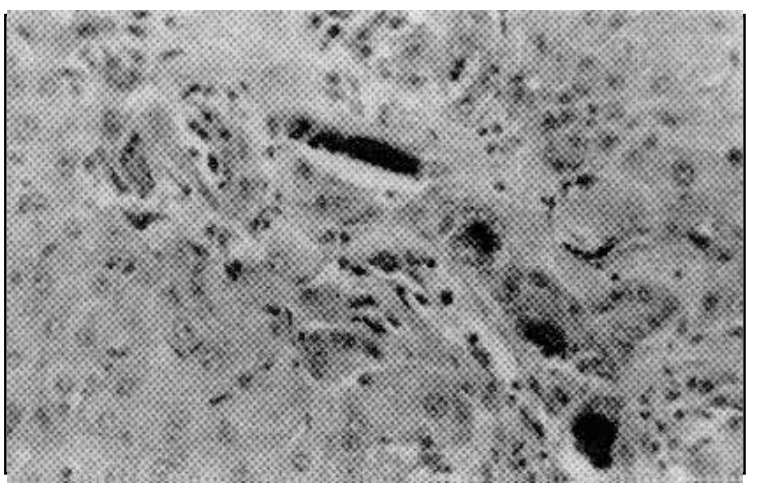

Figura 3 - Fibroplasia, discreta proliferação de células de ductos biliares e retenção biliar intracanalicular em um bovino com fotossensibilização hepatógena do surto 19 . (HE, 10x).

A flora botânica observada nas áreas onde ocorrem os surtos de fotossensibilização hepatógena no sul do Rio Grande do Sul é variável. As espécies vegetais encontradas são observadas, comumente, em campos nativos da região ou como flora de sucessão em áreas utilizadas para o plantio de diferentes culturas. Cynodon dactylon, Axonopus sp., Paspalum spp. e Leersia sp. foram as espécies vegetais prevalentes em restevas de arroz de mais de um ano, enquanto nas restevas novas as espécies prevalentes foram Echinochloa cruzgalis, Juncus bufonius e Leersia hexandra.

Diversas espécies vegetais podem produzir fotossensibilização hepatógena devido seu conteúdo em saponinas como plantas do gênero Panicum spp., (BRIDGES $\boldsymbol{e} \boldsymbol{t} \boldsymbol{a l}$., 1987; KELLERMAN $\boldsymbol{e}$ t al., 1990; MILES et al., 1992), Tribulus terrestris (KELLERMAN et al. 1990; TAPIA et al., 1994), Narthecium ossifragum (MILES et al., 1993; FLAOYEN et al., 1994), Agave lecheguilla (CAMP et al., 1988; MILES et al., 1991), Nolina texana (BRIDGES et al., 1987; ROWE, 1989) e Brachiaria decumbens (LEMOS et al., 1997). Desses vegetais, o único gênero observado nas áreas onde foram observados os surtos da doença foi Panicum, em pequena quantidade. Entretanto, a possibilidade de que a enfermidade fosse causada pelo conteúdo em saponinas presentes neste ou em outros vegetais encontrados em quantidades consideráveis como Axonopus sp. e Echinochloa cruzgalis, foi descartada, uma vez que não foram observados cristais birrefringentes no exame histológico dos fígados dos animais estudados. Esses cristais são característicos da intoxicação por vegetais que contêm saponinas (BRIDGES et $\boldsymbol{a l}$., 1987; KELLERMAN et al., 1990; TAPIA et al., 1994; LEMOS et al., 1997).
Os resultados do estudo epidemiológico realizado, bem como o fato de terem sido descartadas as principais causas conhecidas de fotossensibilização hepatógena apontam para a possibilidade de que a enfermidade seja causada por hepatotoxinas produzidas por fungos, que se desenvolvem em vários tipos de vegetação nativa, ou que ocorre como flora de sucessão em áreas utilizadas para o plantio de arroz ou outras culturas.

A ocorrência estacional de fotossensibilização hepatógena, principalmente no outono e na primavera, sugere a possibilidade de que as variações climáticas possam interferir na manifestação do agente etiológico responsável pela enfermidade. Surtos de fotossensibilização têm sido observados em outonos chuvosos, em bovinos em pastagens de trevo vermelho, sendo sugerido que hepatotoxinas produzidas por fungos como Myrothecium, Alternaria e Rhizoctonia, isolados do trevo tóxico, poderiam ser responsáveis pelo aparecimento da enfemidade (CASTEEL et al., 1991). Do mesmo modo, tem sido sugerido que surtos de fotossensibilização hepatógena, observados em bovinos alimentados com feno de alfafa, ocorram em conseqüência da contaminação do mesmo por diversas espécies de Aspergillus (CASTEEL et al., 1995). Os fungos Chaetomium spp., Pestalotia spp. e Periconia minutissima foram isolados de amostras de vegetação onde ocorreram três dos 19 surtos estudados. No entanto, não foi possível, ainda, avaliar-se a importância dos mesmos na etiologia da enfermidade. Cynodon dactylon contaminado pelo fungo Periconia minutissima tem sido associado à ocorrência de fotossensibilização hepatógena em bovinos (MARASAS \& KELLERMAN, 1978). Essa espécie vegetal estava presente em quantidades consideráveis na maioria das áreas onde ocorreram os surtos, não se podendo descartar, também, a possibilidade de seu envolvimento na etilogia de fotossensibilização hepatógena que ocorre no sul do Rio Grande do Sul.

\section{AGRADECIMENTOS.}

Os autores agradecem ao Sr. Edegar Cardoso, Técnico do CPACT/EMBRAPA pela identificação botânica da vegetação das áreas estudas e ao $\mathrm{CNPq}$ pelo auxílio financeiro para realização desse trabalho.

${ }^{1} \mathrm{~A}$ identificação botânica foi realizada pelo Sr. Edegar Cardoso - Botânico do CPACT/EMBRAPA.

\section{REFERÊNCIAS BIBLIOGRÁFICAS}

BRIDGES, C.H., CAMP, B.J., LIVINGSTON, C.W. et al.. Klein grass (Panicum coloratum L.) Poisoning in sheep. Vet Pathol, v. 24, p. 525-531. 1987. 
CAMP, B.J., BRIDGES, C.H., HILL, D.W. et al.. Isolation of a steroidal sapogenin from the bile of a sheep fed Agave lecheguilla. Vet Hum toxicol, v. 30, n. 6, p. 533-535, 1988.

FLAOYEN, A., MILES, C.O., SMITH, B.L. Alved in lambs in Norway. In: COLEGATE S. M., DORLING P. R. Plantassociated toxins. Cab international U-K p. 293-296, 1994.

HOLLAND, P.T., MILES, C.O., MORTIMER, P.H. et al... Isolation of the steroidal sapogenin epismilagenin from the bile of sheep affected by Panicum dichotomiflorum toxicosis. J Agric Food Chem, v. 39, p. 1963-1965, 1991.

CASTEEL, S.W., WEAVER, A.D., MILLS, L.L. et al. Photosensitization outbreak in Shorthorn calves in Missouri. J Vet Diagn Invest, v. 35, p. 180-182, 1991.

CASTEEL, S.W., ROTTINGHAUS, G.E., JOHNSON, G.C. et $\boldsymbol{a l}$. Liver disease in cattle induced by consumption of moldy hay. Vet Hum toxicol, v. 37, n. 3, p. 248-251, 1995

KELLERMAN, T.S., COETZER J.A.W., NAUDÉ T.W. Plant poisonings and mycotoxicoses of livestock in Southern Africa. Republic of Southern Africa: Oxford University Press. p. $20-42,1990$.

KELLY, W.R. Liver and biliary system. In: Jubb K.V.F., Kennedy P.C., Palmer N. Pathology of domestic animals. $4^{\mathrm{a}}$ ed., Academic Press, Inc. California. Volume 2, p. 382-388. 1993

LEMOS, R.A.A., SALVADOR, S.C., NAKAZATO, L. Photosensitization and crystal associated cholangiohepatopathy in cattle grazing Brachiaria decumbens in Brazil. Vet Human Toxicol, v. 39, n. 6, p. 376-377, 1997.

MARASAS, W.F.O., KELLERMAN, T.S. Mycotoxicoses in cattle. Photosensitivity in cattle. In: Wyllie T.D., Morehouse L.G., ed. Mycotoxic fungi, Mycotoxins, Mycotoxicoses: Mycotoxicoses of Domestic and Laboratory Animals, Poultry and Aquatic Invertebrates and Vertebrates. New York. Marcel Dekker Inc.v. 2, p. 73-84, 1978.

MÉNDEZ, M.C. Intoxicação por Senecio spp. In: RIET-
CORREA F., MÉNDEZ M.C., SCHILD A.L. Intoxicações por plantas e micotoxicoses em animais domésticos. Editorial Agropecuária Hemisferio Sur S. R. L., Uruguai, p. 43-102, 1993.

MILES, C.O., MUNDAY, S.C., HOLLAND P.T., et al.. Identification of a sapogenin glucuronide in the bile of sheep affected by Panicum dichotomiflorum toxicosis. New Zealand Vet J, v. 39, p. $150-152,1991$.

MILES, C.O., WILKINS, A.L., MUNDAY, S.C. $\boldsymbol{e t}$ al.. Identification of insoluble salts of the B-D-glucuronides of episarsasapogenin e epismilagenin in bile of lambs with alved and examination of Narthecium ossifragum, Tribulus terrestris and Panicum miliaceum for sapogenins. J of Agric and Food Chem, v. 41, p. 914-917, 1993.

ROWE, L.D. Photosensitization problems in Livestock. Veterinary Clinics of North America: Food Animal Practice, v. 5, n. 2, p. 301-323, 1989.

SCHILD, A.L., RIET-CORREA, F., MÉNDEZ, M.C. et al.. Doenças diagnosticadas pelo Laboratório Regional de Diagnóstico no ano de 1991. Boletim do Laboratório Regional de Diagnóstico, $\mathrm{N}^{\mathrm{o}} 12$. Editora Universitária. Pelotas, RS. p. 68, 1992.

TAPIA, M.D., GIORDANO, M. ${ }^{a}$, GUEPER, H.G. An outbreak of hepatogenous photosensilization in sheep grazing Tribulus terrestris in Argentina. Vet Human toxicol, v. 36, p. 311-313, 1994.

TOKARNIA, C.H., DÖBEREINER, J., SILVA, M.F. Plantas tóxicas conhecidas em outras regiões do Brasil e que ocorrem também na Região Amazônica, onde, porém, são de menor importância. In: TOKARNIA, C.H., DÖBEREINER, J., SILVA M.F. Plantas tóxicas da Amazônia a bovinos e outros herbívoros. MANAUS: Instituto Nacional de Pesquisas da Amazônia. p. 69-75, 1979.

YAGER, J.A., SCOTT, D.W. The Skin and Appendages In: JUBB K.V.F., KENNEDY P.C., PALMER, N. Pathology of domestic animals. $4^{\text {th }}$ ed. Orlando: Academic Press 1: 531705,1993 .

Ciência Rural, v. 30, n. 1, 2000. 